\title{
Nanoindentation study of the interfacial zone between cellulose fiber and cement matrix in extruded composites
}

\author{
R.S. Teixeira a, *, G.H.D. Tonoli ${ }^{\mathrm{b}}$, S.F. Santos ${ }^{\text {c }}$, E. Rayón ${ }^{\mathrm{d}}$, V. Amigó ${ }^{\mathrm{d}}$, H. Savastano Jr. ${ }^{\mathrm{e}}$, \\ F.A. Rocco Lahr ${ }^{\text {a }}$ \\ ${ }^{a}$ University of São Paulo (USP), Department of Structural Engineering, São Carlos School of Engineering, Brazil \\ ${ }^{\mathrm{b}}$ Federal University of Lavras (UFLA), Department of Forest Science, Brazil \\ c São Paulo State University (UNESP), School of Engineering, Department of Materials and Technology, Brazil \\ ${ }^{\mathrm{d}}$ Universitat Politècnica de València (UPV), Department of Mechanical and Materials Engineering, Spain

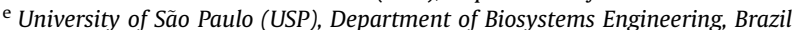

\section{A R T I C L E I N F O}

\section{Article history:}

Received 19 August 2016

Received in revised form 14 July 2017

Accepted 29 September 2017

Available online 3 October 2017

\section{Keywords:}

Vegetable fiber

Microstructure

Mechanical properties

Ordinary Portland cement

Transition zone

\begin{abstract}
A B S T R A C T
The present study shows the application of the nanoindentation technique to evaluate the properties of the cellulose fiber-cement matrix interfacial zone in composites prepared with an auger extruder. The degree of strength of the bond between fiber and matrix is recognized as important variable that influences macro-mechanical properties, such as modulus of rupture and toughness of cement based composites. The nanoindentation measurements showed the highest hardness and elastic modulus in the part inner of the cellulosic fiber after hydration process due to precipitation and re-precipitation of cement hydration products. These results indicate that mineralization of the cellulosic fibers can affect the stress distribution and interfacial bond strength in the cement based composite.
\end{abstract}

๑) 2017 Elsevier Ltd. All rights reserved.

\section{Introduction}

It is widely accepted that concrete at the mesoscopic scale should be treated as a three-phase composite material constituted by bulk hardened cement paste, aggregates and an interfacial transition zone (ITZ) between these two [1]. Therefore, traditional ITZ is the region of the cement matrix around the aggregate particles, which is perturbed by the presence of the aggregate. Its origin lies in the packing of the cement grains against the much larger aggregate, which leads to a local increase in porosity and predominance of smaller cement particles in this region. The ITZ is region of gradual transition and is highly heterogeneous, nevertheless the average microstructural features may be measured [2].

The cementitious composites reinforced with cellulosic fibers are complex materials. Thus, cement based composite design must be considered for the interrelation between interfacial transition zone, fibers, matrix and processing method. Particle and fiber size distribution, particles and fibers packing and rheological behavior

\footnotetext{
* Corresponding author.

E-mail address: ronaldostx@yahoo.com.br (R.S. Teixeira).
}

of the cement paste with fibers in the fresh state also interfere on the interfacial transition zone of the hardened cement based composite. Furthermore, changes in the mechanical properties over time can occur due to microstructural changes in the fiber-matrix interface and bulk, as a consequence of the continued hydration process that occurs in the fiber surroundings, i.e. if the interfacial transition zone becomes denser due to re-precipitation of cement hydration products in the porous layers [3]. Therefore, in this manuscript an interfacial transition zone (ITZ) terminology is related to a region between bulk hardened cement paste and cellulosic fiber.

Kraft pulp fiber-reinforced cement-based materials have being increasingly used in most developing countries as construction materials [4-6]. Fibers usually increase mechanical strength and the capacity of cement based composite to absorb energy through the distribution of microcracks into the material. The bonding between cellulose fiber and Portland cement plays a major role in the transference of the load from the matrix to the reinforcement, impacting the mechanical behavior of the resulting fiber-cement material. This bonding can be of physical (mechanical interlocking) or chemical (mainly hydrogen bonds) nature, or a 
combination of both [7].

Extrusion process has a potential of producing fiber reinforced cementitious composites with higher performance compared to the traditional slurry dewatering processes such as Hatschek and Flow-on methods. Several advantages of extrusion molding can be pointed for manufacturing of fibrous composites: (i) low implementation cost; (ii) low capillary porosity of extruded composites; and (iii) low water/cement ratio, which plays a significant role for improving of the fiber-matrix interface zone [8-10]. As mentioned above, the control of fiber-matrix interface zone in extruded composites depends on cellulosic fibers and matrix constituent's properties, cure procedure as well as weathering conditions that the composite are exposed. Previous studies highlighted that water/cement ratio influences the interface zone thickness and that lower porosity may increase composite strength and matrix toughness [9-12]. Therefore, the optimization of the interfacial zone is not an easy task since it is necessary to satisfy the equilibrium between fiber-matrix adhesion and fiber pull-out. In addition, there is still a lack of information about the consequences of the different types of interface zone between cellulose fibers and matrix, on composite mechanical properties. Thus, an effort is required in order to understand the mechanical properties at fibermatrix transition zone.

The macroscale mechanical properties of bulk materials are dependent on the properties of their microscale/nanoscale constituents and the interface between these constituents. Microindentation technique is one of the developing tests that have been used for evaluating mechanical characteristics of microsized zones in diverse cement based composites [13-15]. Nevertheless, microindentation is not capable to detect mechanical differences at the interfaces between cement matrix and reinforced fibers, due to some limitations, such as a resolution of microindentation system in terms of load is about $5.0 \mathrm{mN}$, to analyze some structural features because of the heterogenity of the specimen, inadequate spacing between indents or form edges, operator's visual acuity. Quasistatic nanoindentation has become the standard technique used for nanomechanical characterization of small volumes of material, such as elastic modulus, hardness at the nanoscale. It is used machines that can record small load and displacement with high accuracy and precision, during loading and unloading can be continuously monitored with high resolution in the nanonewton and nanometer ranges. In this technique is used usually the Berkovich tip is a 3-sided pyramid that have an apex appropriate for investigating the interface transition zone between fiber and matrix. Therefore, nanoindentation technique can contribute to quantitatively measure the underlying source of the bulk response at the nanoscale in cement based composites that are heterogeneous material from both a chemical composition and nanoscale structure standpoint. Being able to evaluate at this scale allows micro and nano structural "tuning" to be performed to optimize bulk properties $[16,17]$. The aim of this study was to evaluate the interfacial zone between fibers to cement matrix in extruded composites reinforced with eucalyptus pulp, using a nanoindentation technique allied with microscopic examinations.

\section{Experimental}

\subsection{Materials}

Unbleached unrefined eucalyptus (Eucalyptus grandis) Kraft pulp was provided by Fibria S/A, Brazil. The cellulose pulp was collected directly from the mill, prior to drying and pressing. It was extensively washed with water and centrifuged to remove any residual chemicals from the pulping processes.

Eucalyptus pulps were analyzed about morphology (length and width) and concentration of particles (fibers per gram and content of fines). A fine element (small particles with length lower than $200 \mu \mathrm{m}$ that are commonly called fines, which also contain bandlike materials from both primary wall and secondary wall layers of the fibers) was detected in the pulp with dimensions lower than those of fibers. Fines do not contribute significantly to cement based composite strength but act more as filler [18]. Physical characteristics of the unbleached eucalyptus pulp are showed in Table 1.

\subsection{Composite mix design}

Formulation used in the composite production was based on previous study [8], and is described in Table 2.

Portland cement and limestone particles distribution was performed by laser particle size analyzer (Malvern Mastersizer S long bed, version 2.19). Cement and limestone particles showed $50 \%$ of their size below $11 \mu \mathrm{m}$ and $16 \mu \mathrm{m}$ respectively.

Hydroxypropylmethylcellulose (HPMC) from Aditex, is a superplasticizer which disperses cement particles, reducing the flow stress and the viscosity of the cement paste. Polyether carboxylic provided by Grace, commercially called ADVA 170, is an additive which reduces the surface tension of the water and thus causes an increase in the surface area of the liquid which improves the water absorption, forming a lubrication layer between the wall of the extruder and the surface of the fiber cement board. HPMC with 86,000 average molecular weight and 5.39 cPs viscosity (at $2 \%$ concentration in water at $20{ }^{\circ} \mathrm{C}$ ) and polyether carboxylic commercially named ADVA 170, were used as rheological modifiers in fiber-cement, with dosage of $1 \mathrm{wt} \%$ of the total mass of the particulate inorganic materials (Portland cement and limestone) to promote the pseudo-plastic behavior of the composite, which, in turn, enabled the extrusion process.

\subsection{Composite extrusion}

The mass was mixed in a mechanical Eirich intensive mixer (capacity of $10 \mathrm{~L}$ ) for $5 \mathrm{~min}$ at $125 \mathrm{rpm}, 5 \mathrm{~min}$ at medium velocity (220 rpm) and finally $5 \mathrm{~min}$ at high velocity (450 rpm). The watercement $(\mathrm{w} / \mathrm{c})$ ratio was 0.33 . The composite mixture was transferred to a Verdes 051 extruder (Fig. 1a-b). The speed of the extruder was $4 \mathrm{~mm} / \mathrm{s}$; die width/diameter ratio was 3.3. Composites were molded in $15 \mathrm{~mm} \times 50 \mathrm{~mm} \times 200 \mathrm{~mm}$ plates. The illustration of the chamber parts of the extruder is presented in Fig. 1c.

The composite mixture was re-circulated into the extruder for 5 min before tailoring the samples. Pads with $15 \mathrm{~mm} \times 50 \mathrm{~mm} \times$ $200 \mathrm{~mm}$ were cured at water vapor saturated environment (in sealed plastic bags) at $25 \pm 2{ }^{\circ} \mathrm{C}$ for two days. Subsequently, the specimens were maintained in water vapor saturated environment (in sealed plastic bags) and placed in a chamber at $45^{\circ} \mathrm{C}$ for five days (thermal curing) totalizing 7 days of cure [21].

\subsection{Microstructure characterization}

The specimens were cut out from the middle section of a larger volume of fiber cement, with minimal deformation, by using a precision cutter, Buehler, model Isomet, with precision diamond saw, 15LC, and using an isopropyl alcohol based cutting fluid to cut. This method provides roughness smaller. The specimens were embedded in epoxy resin (MC-DUR1264FF) previously to be visualized in a scanning electron microscope (SEM). A final polishing was carried out using sequentially $8-4 \mu \mathrm{m}, 4-2 \mu \mathrm{m}$ and 1-0 $\mu \mathrm{m}$ diamond abrasives, as reported elsewhere [22,23]. The polished samples were carbon coated before being analyzed in a JEOL JSM6300 electron microscope with acceleration voltage of $20 \mathrm{kV}$. A 
Table 1

Physical characteristics of the unbleached eucalyptus pulp [18].

\begin{tabular}{|c|c|c|c|c|}
\hline Average length (mm) & Average width $(\mu \mathrm{m})$ & Aspect Ratio & Fibrous material ( $10^{6}$ fibers/g) & Content of fines by mass (\%) \\
\hline $0.83 \pm 0.05$ & $16.4 \pm 0.2$ & 51 & $18.17 \pm 1.11$ & $25.7 \pm 0.6$ \\
\hline
\end{tabular}

Table 2

Mix design used in the production of the composites.

\begin{tabular}{ll}
\hline Raw material & Content (\% by mass) \\
\hline Portland cement (CPV-ARI) $^{\mathrm{a}}$ & 70 \\
Limestone filler $^{\mathrm{b}}$ & 27 \\
Unbleached eucalyptus pulp $^{\mathrm{c}}$ & 3 \\
\hline
\end{tabular}

a ASTM C150 type I [19], provided by Caue.

b Itaú.

c Fibria S.A.

back-scattered electron (BSE) detector was used to observe the morphological features on the cross-section and polished surfaces. BSE imaging permits the identification of cementitious phases since the electron scattering change. Dark and light areas are related to lighter and heavier elements respectively. Energy dispersive spectrometry (EDS) analysis was performed in order to identify the chemical composition in different spots on the same polished surface specimens.

\subsubsection{Atomic force microscopy characterization (AFM)}

In contrast to ductile material, cement based composite have regions with higher hardness, lower ductility, and a basically brittle nature. Due to the brittleness, cellulosic fibers and porosity of the composite it is quite often difficult to cut and polish. All areas of the specimens observed by nanoindentation were cut and polished with uniformity and carefully to avoid any pullout of fibers, but as the composite is heterogeneous the response of each region was different according to its resistance. Specimens for AFM characterization were cut with same system mentioned above and embedded in polyacrylamide. The semi-automatic polisher was used to adjust polishing velocity and pressure, i.e. all regions were submitted to same conditions of preparation. Then, the dried surfaces were grinded in a sequence of SiC papers (grit \#500, \#1000, \#2000 and \#4000) and polished in a cloth sequentially with $9 \mu \mathrm{m}$, $6 \mu \mathrm{m}$ and $3 \mu \mathrm{m}$ diamond sprays. Finally, the specimen surfaces were cleaned by washing in alcohol and ultrasonic bathing.

The characterization of the fiber-matrix interface zone was carried out using the tapping-mode atomic force microscopy (TMAFM) to obtain height and phase imaging data simultaneously, with Nanoscope III-Digital Instruments. Silicon cantilever with spring constant of around $70 \mathrm{~N} / \mathrm{m}$ and a scan area of $15 \mu \mathrm{m} \times 15 \mu \mathrm{m}$ was used. Samples were prepared in the laboratory environment with temperature around $25{ }^{\circ} \mathrm{C}$ and relative humidity between $50 \%$ and $65 \%$. AFM images were obtained in the same laboratory environment conditions. The test locations were guided by means of an incorporated optical light microscope.

\subsection{Nanoindentation tests}

Specimens for nanoindentation tests were prepared the same methodology that specimens to AFM characterizations. Nanoindentation was performed in an Agilent G-200 instrument working in continuous stiffness measurement (CSM), configured at $2 \mathrm{~nm}$ of harmonic amplitude, $45 \mathrm{~Hz}$ frequency, and using a Berkovich indenter. The test locations were guided by means of an incorporated optical light microscope. To rule out the influence of surface morphology, the indentation depth should be much greater than the characteristic size of surface roughness to avoid errors and size effect in the calculations [17]. Tests were programmed to reach from 100 to $300 \mathrm{~nm}$-indented depths until the maximum depth of $1000 \mathrm{~nm}$. Therefore, the depth of the imprint spots used in the nanoindentation was to minimize surface roughness of the samples. Analyses were performed with $8 \mathrm{~nm}$ distance between the measurement points [17]. It was performed more than 20 analyses for each region of the composite (bulk matrix, interface or transition zone, anhydrous grain and cellulose fibers).

To guarantee a significance results for nanoindentation tests were choose under a completely randomized design the ITZ areas to analyze a linear sequence with four regions (transition zone, cellulose fiber, transition zone, bulk matrix and anhydrous grain or follow sequence: anhydrous grain, bulk matrix, cellulose fiber, transition zone) and twenty replications. The effects of hardness and elastic modulus were compared via statistical contrast by student test at $5 \%$ of significance [17]. The ACTION statistical program was used. Therefore, the interfaces towards fibers and matrix were studied in greater detail.

\section{Results and discussion}

\subsection{Chemical and microstructure characterization}

Fig. 2 shows SEM-BSE micrographs of the extruded composites. Energy dispersive X-ray spectroscopy (EDS) analysis (Fig. 2a) indicate that fiber-matrix interfacial zone presents high $\mathrm{Ca} / \mathrm{Si}$ ratio (between 4 and 5), indicating the possible correspondence with $\mathrm{Ca}(\mathrm{OH})_{2}$ crystals with carbonated products, such as calcite, as corroborated by AFM analysis (Fig. 3) and according to Ruiz-Agudo et al. [24]. This interfacial zone rich in $\mathrm{Ca}(\mathrm{OH})_{2}$ crystals has been widely reported in literature for cementitious composites [25-29]. Bulk matrix revealed an expected lower $\mathrm{Ca} / \mathrm{Si}$ ratio (approximately 2.5 ) as observed in Fig. 2b. The phase composition of the anhydrous grains and matrix are shown in Fig. 4a and b, respectively. Spot B presents higher concentration of $\mathrm{SiO}_{2}$ and $\mathrm{CaO}$ due to the hydration products of cement in relation to the spot A (region of the anhydrous grain).

\subsection{Mechanical characterization by nanoindentation}

Figs. 5a and 6a present the micrographs of the nanoindentation imprints done along the bulk section of the composites. The spots numbered between 1 and 10 (Fig. 5a), 25-61 (Fig. 5a) and 81-90 (Fig. 6a) represent the bulk matrix of the composite. The spots 15-16 (Fig. 5a), 20-22 (Fig. 5a) and 101-110 (Fig. 6a) represents the interfacial zone. The spots 16-19 (Fig. 5a) and 91-100 (Fig. 6a) represents the cellulosic fiber, while 62-70 (Fig. 5a) and 81-90 (Fig. 6a) are spots related to anhydrous grains. The individual values of elastic modulus (E) acquired for each spot are summarized in Figs. $5 b$ and $6 b$; while the individual values of hardness $(H)$ is presented in Figs. $5 c$ and $6 c$.

Table 3 shows the average and standard deviation values of elastic modulus and hardness obtained from nanoindentation in the different regions studied. The indent spots in the bulk matrix led to elastic modulus of around $70 \mathrm{GPa}$ and hardness of around $5 \mathrm{GPa}$. These results are similar to those found by Silva et al. [17], who studied nanoindentation in concrete specimens. The bulk 

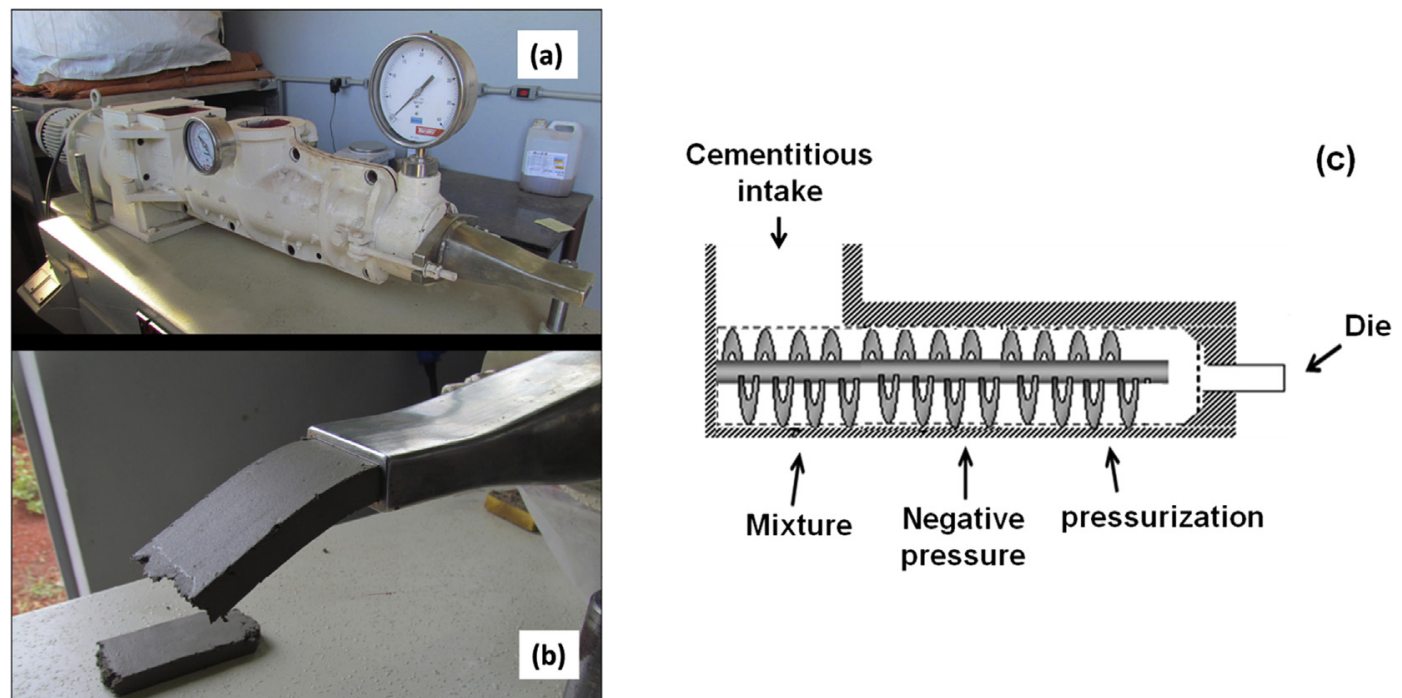


from Ref. [20]).
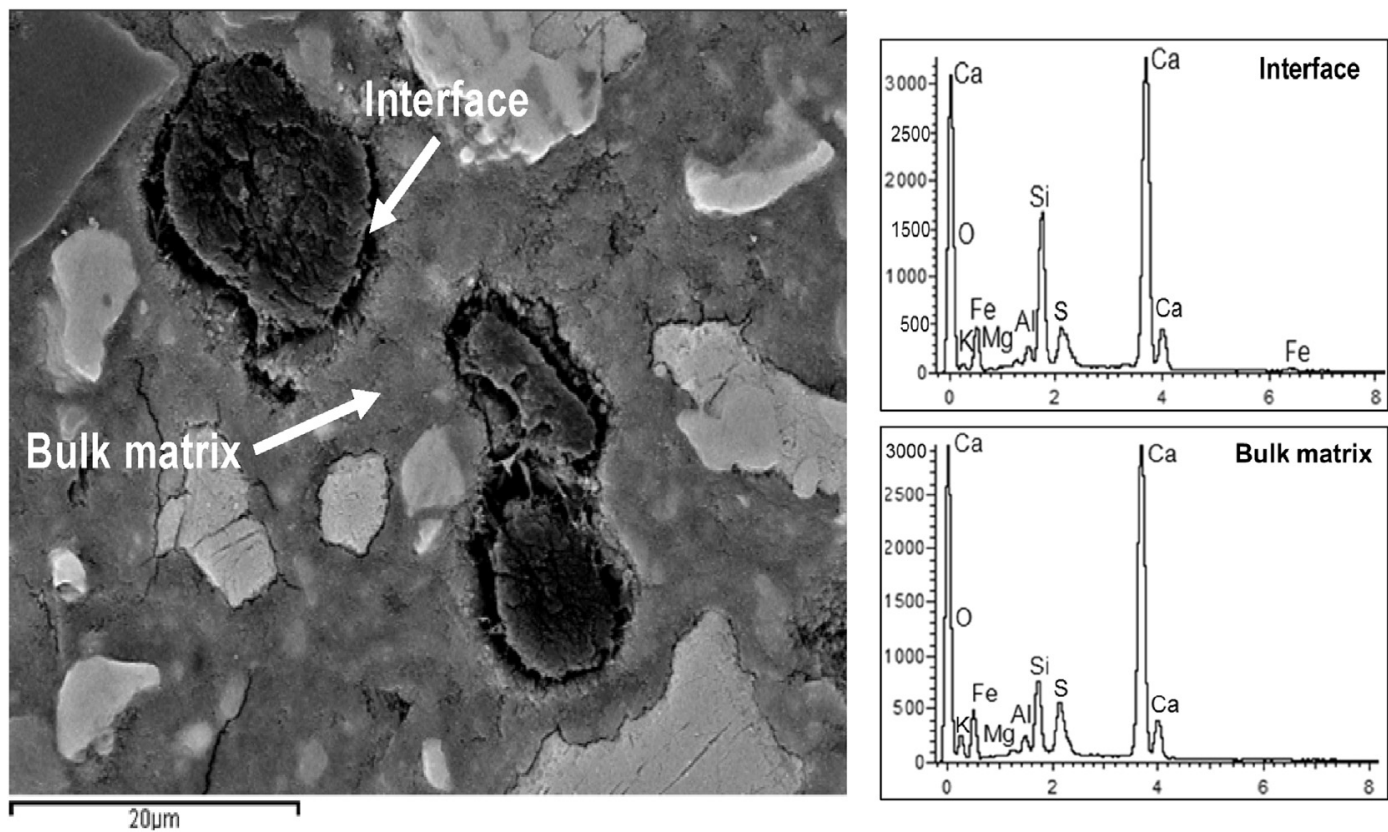

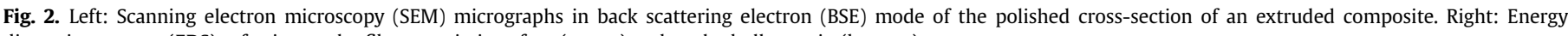
dispersive spectra (EDS) referring to the fiber-matrix interface (upper) and to the bulk matrix (bottom).

matrix of composites based on Portland cement normally presents calcium silicate hydrates (C-S-H) and calcite phases as main components, which have higher rigidity and relative lower porosity than other phases such as $\mathrm{Ca}(\mathrm{OH})_{2}$ and ettringite that are formed by poorly packed structures. This is why the spots correspondent to the interfacial/transition zone presents lower elastic modulus ( $17 \mathrm{GPa})$ and hardness ( $0.4 \mathrm{GPa})$. These results of the elastic modulus and hardness vary in relation to the distance of the transition zone, as showed in Fig. 5. Similar result was found by Wang et al. [30] that studied nanoindentation technique in concrete reinforced with steel fibers. The values of hardness in the
$11-12,23-26$ indent spots near to the interfacial zone are smaller than those in the matrix region, which are also related to the higher porosity in the interfacial zone, resultant of the low adhesion between fiber and matrix [31,32].

Other important observation from this study in nanoscale level is related to the hydration of the cement grains in the composite. The incorporation of water during the mixing of the composite constituents leads to cement hydrate grains that have much lower average atomic numbers than cement grains that were not completely hydrated (anhydrous grains). Then, strong contrast is obtained between unreacted (anhydrous) and reacted material 


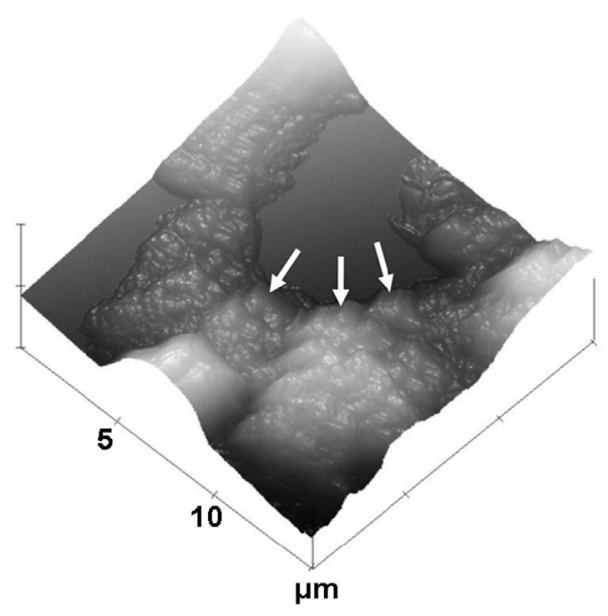

Fig. 3. AFM topography image of the interface fracture. Arrows show the possible $\mathrm{Ca}(\mathrm{OH})_{2}$ with carbonated production in the interfacial zone between the cellulose fiber and cement matrix.

(hydrates) [33]. Anhydrous grain shown in Table 3 presents elastic modulus of around $90.0 \mathrm{GPa}$ and hardness of around $4.5 \mathrm{GPa}$, which was not significantly different from average values of hydrated bulk matrix. Velez et al. [34] also studied nanoindentation in cement and did not find differences between hardness and elastic modulus in anhydrous phases such as alite $\left(\mathrm{C}_{3} \mathrm{~S}\right)$, calcium aluminate $\left(\mathrm{C}_{3} \mathrm{~A}\right)$ and belite $\left(\mathrm{C}_{2} \mathrm{~S}\right)$.

The highly alkaline pore water within the fiber-cement interface can induce the cellulose fibers stiffening. It occurs because cellulose fibers are hydrophilic and absorb water rich in cement hydration products, leading to the mineralization phenomenon proposed elsewhere [35-37]. This phenomenon is related to hydrophilic nature of the cellulose fibers. Therefore, this phenomenon is related to the hydrophilic nature of the cellulose fibers. This nature depends on surface nature, surface porosity and lumens the inner of the cellulose fiber. The internal humidity in the fiber can promote a continued hydration process, with precipitation and reprecipitation internally, such as $\mathrm{C}-\mathrm{S}-\mathrm{H}$, portlandite and calcites, as suggest by Fig. 7a and b. Fig. 7a shows hydration products within the cell wall of cellulosic fibers, while the EDS spectra (Fig. 7b) in
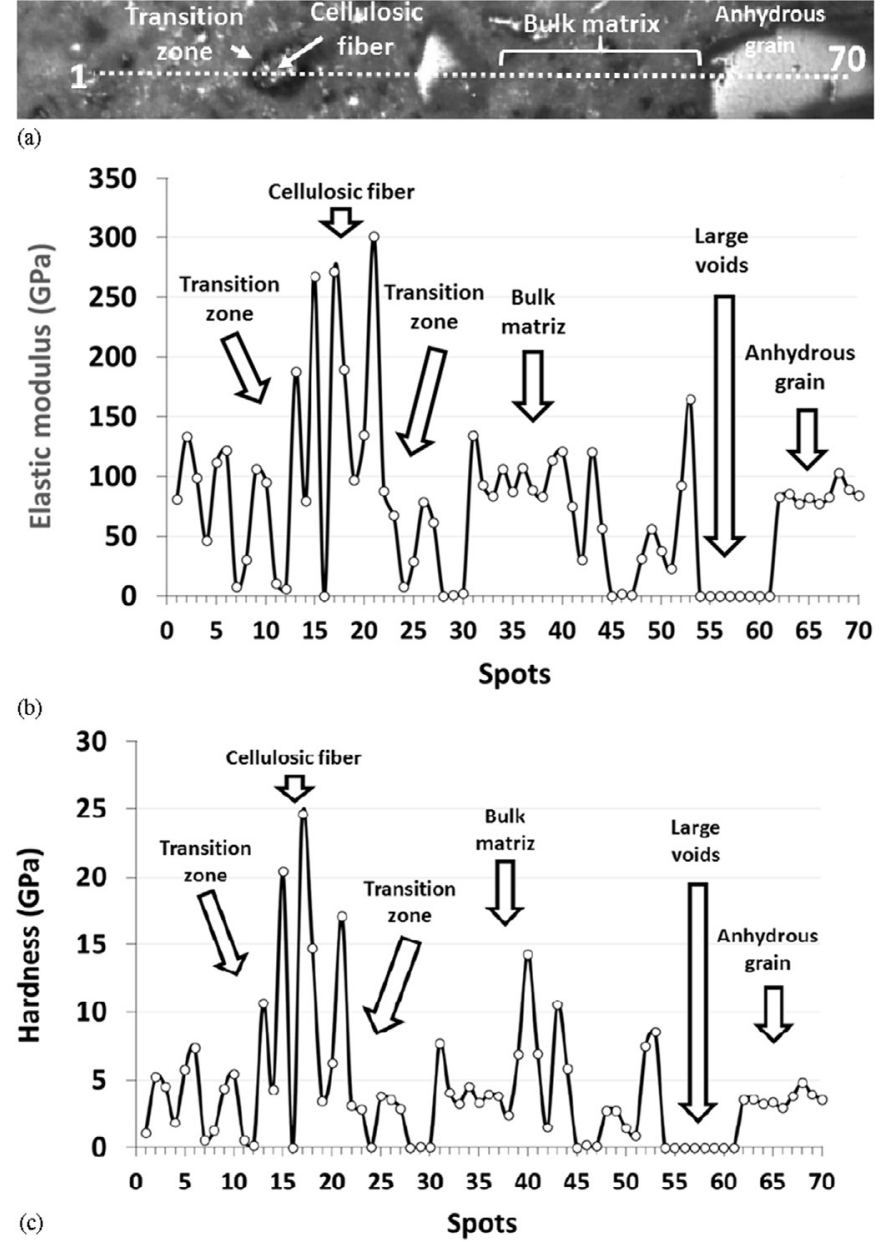

Fig. 5. (a) Light micrograph of the nanoindentation spots applied in line along the bulk section of the composite; (b) individual values of elastic modulus for each spot of the micrograph; and (c) individual values of hardness for each spot of the micrograph.

the spots 1 (upper) and 2 (bottom) proves the large amounts of $\mathrm{Si}$ and $\mathrm{Ca}$ into the cellulose fibers. It explains the higher values of

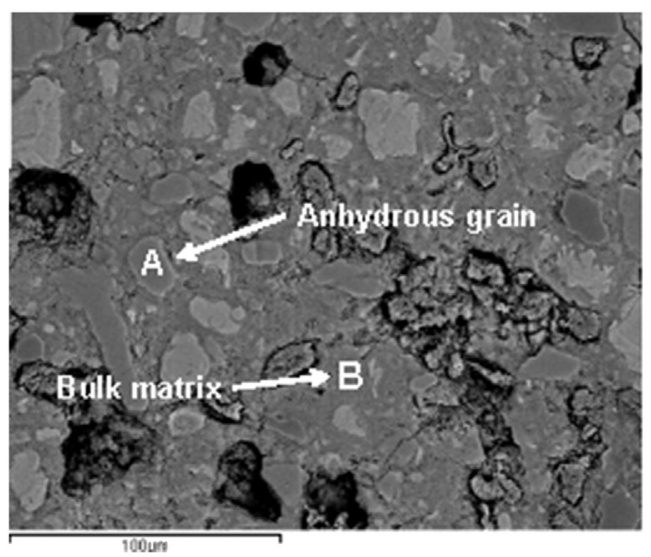

\begin{tabular}{|cc|}
\hline \multicolumn{2}{|c|}{ Spot A } \\
Elements & Composition weight \% \\
$\mathrm{MgO}$ & 13.94 \\
$\mathrm{Al}_{2} \mathrm{O}_{3}$ & 13.13 \\
$\mathrm{SiO}_{2}$ & 18.53 \\
$\mathrm{CaO}$ & 51.53 \\
$\mathrm{FeO}$ & 2.58 \\
\hline \multicolumn{3}{|c|}{ Spot B } \\
Elements & Composition weight \% \\
$\mathrm{MgO}_{9}$ & 3.15 \\
$\mathrm{Al}_{2} \mathrm{O}_{3}$ & 2.20 \\
$\mathrm{SiO}_{2}$ & 26.51 \\
$\mathrm{CaO}$ & 66.63 \\
$\mathrm{FeO}$ & 1.53 \\
\hline
\end{tabular}

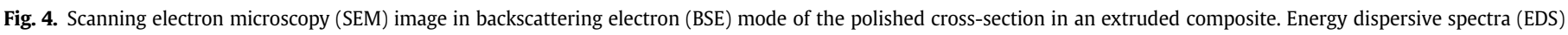
refer to the composition of the anhydrous grain (spot A) and bulk matrix region (spot B). 


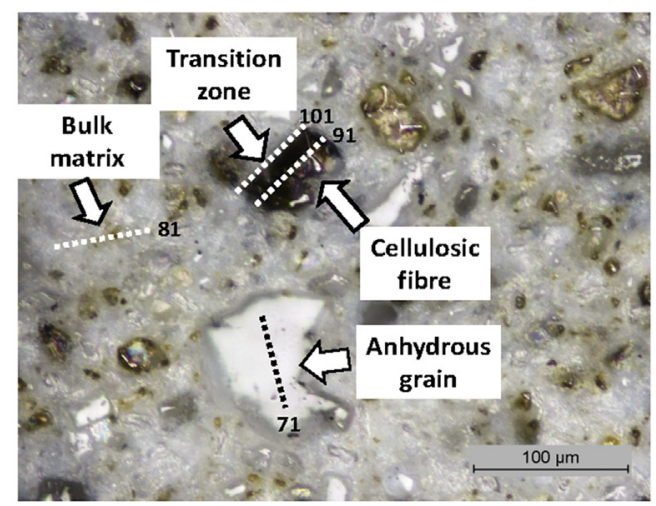

(a)

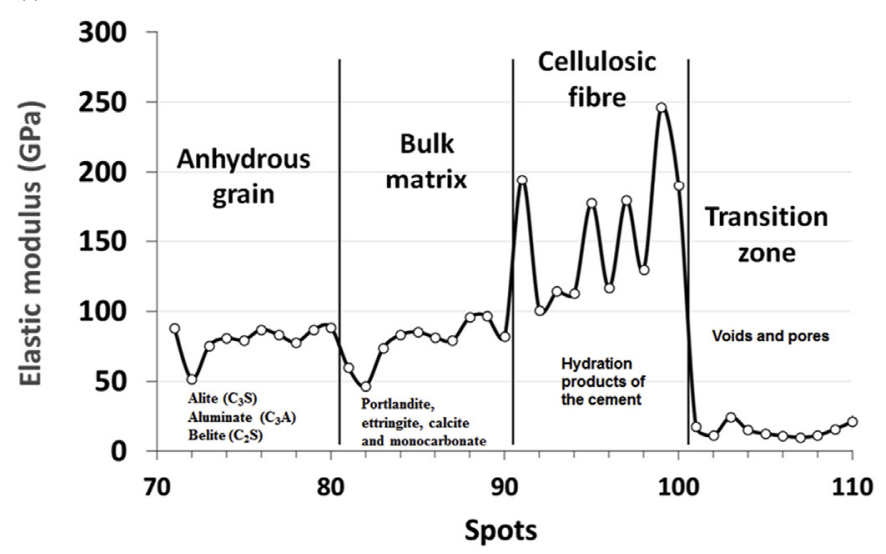

(b)

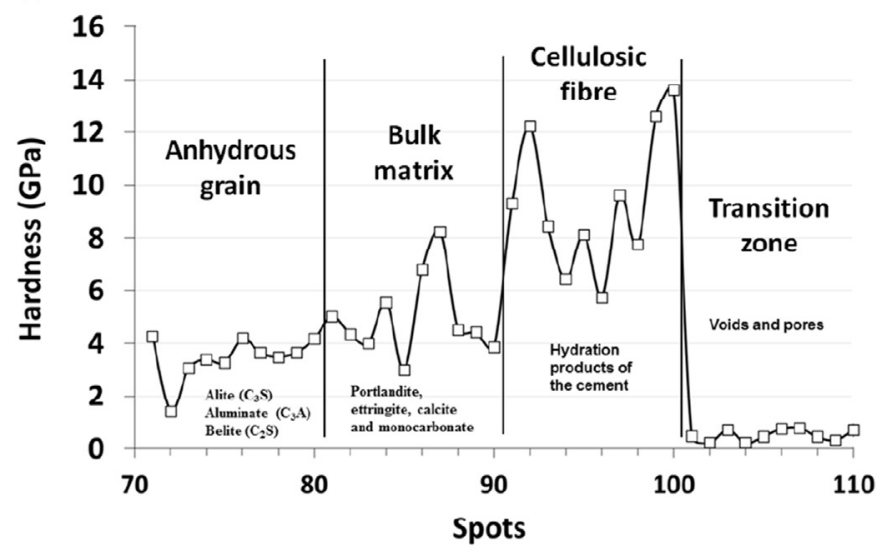

(c)

Fig. 6. (a) Light micrograph of the nanoindentation spots applied in line along the different structures (anhydrous grain, bulk density, cellulose fiber and interfacial/ transition zone between fiber and matrix) of the composite; (b) individual values of elastic modulus for each spot of the micrograph; and (c) individual values of hardness for each spot of the micrograph. elastic modulus ( $\sim 144 \mathrm{GPa}$ ) and hardness ( $\sim 9 \mathrm{GPa}$ ) observed for the nanoindentation spots related to the cellulosic fiber regions. Therefore, the average elastic modulus of mineralized cellulose fibers can reach higher values than cement bulk matrix. The increase of stiffness of the cellulose fibers is a drawback because can induce the loss of their reinforcement capacity. The efficiency of stress transfer from matrix to fiber that is of fundamental importance in determining the mechanical properties of short fibre reinforced composite is prejudiced. This result explain the premature loss of ductility/toughness and increase of stiffness of composites reinforced with cellulose fibers widely reported in literature [22,23,38,39].

Therefore, the fiber to matrix bonding is impaired because cellulose fiber tends to exchange water with the matrix system by capillary action, leading to high dimensional variation and detachment of the fiber surface from the matrix, as showed in Fig. 7a, creating voids that explain the low results of elastic modulus and hardness in the transition zone. Finally, the present observations may state that an optimal situation would be the cellulose fibers protection from excessive water absorption, what can be achieved by less hydrophilic surfaces (either natural or after an adequate treatment) and without losing the fiber bridging. Fiber bridging is important to guarantee the expend of energy during fiber pullout, which leads to composite ductility.

\section{Conclusions}

High values of elastic modulus and hardness, $144 \pm 48.9 \mathrm{GPa}$ and $9 \pm 2.5 \mathrm{GPa}$, respectively, was found by means of nanoindentation imprints in the cellulose fiber, because of the majority presence of $\mathrm{C}-\mathrm{S}-\mathrm{H}$, portlandite and calcite phases. Then, cellulose fibers absorb water rich in cement hydration products, which induce the cellulose fiber stiffening by the precipitation and re-precipitation of hydration products into the fiber, these phenomenon lead to the socalled mineralization process. The increase of stiffness of the inner part of the cellulose fibers is a drawback because can induce the loss of their reinforcement capacity. . The present finding contributes to better understanding the interface properties between fiber and matrix that affect cellulose fiber-cement materials performance, in terms of macroscopic mechanical properties. It is difficult to obtain the effective elastic modulus these composites because the low adhesion between the hydrophilic cellulose fibers and cement matrix, mineralization of the cellulose fiber and consequently a significant difference of elastic modulus between matrix, interface transition zone (ITZ), and cellulose fiber. These results indicate a clear modification of the contribution of the cellulosic fiber in the stress distribution and interfacial bond strength in the cement based composite. Therefore, it is still a challenge to modify nano and micro structures of the ITZ in order to improve mechanical properties in macro scale of the extruded fiber-cement composites.

Table 3

Average and standard deviation values of elastic modulus and hardness obtained for each structure of the composite by nanoindentation technique. ${ }^{\mathrm{A}}$

\begin{tabular}{lll}
\hline Structures & Elastic modulus $(\mathrm{GPa})$ & Hardness $(\mathrm{GPa})$ \\
\hline Interfacial/transition zone & $17.2 \pm 5.6 \mathrm{c}$ & $0.4 \pm 0.2 \mathrm{c}$ \\
Bulk matrix & $72.7 \pm 14.3 \mathrm{~b}$ & $5.3 \pm 1.8 \mathrm{~b}$ \\
Anhydrous grain & $89.9 \pm 17.1 \mathrm{~b}$ & $4.5 \pm 1.9 \mathrm{~b}$ \\
Cellulosic fiber & $144.3 \pm 48.9 \mathrm{a}$ & $8.9 \pm 2.5 \mathrm{a}$ \\
\hline
\end{tabular}

\footnotetext{
${ }^{\mathrm{A}}$ Lowercase letters (a, b and c) in the same column represent comparisons between conditions of the composites. Different letters indicate significant differences amongst the properties of the composites.
} 



(a)

(b)

Fig. 7. (a) Scanning electron microscopy (SEM) micrographs in back scattering electron (BSE) mode of the polished cross-section of an extruded composite; and (b) energy dispersive spectra (EDS) of the spots 1 and 2 in the SEM micrographs.

\section{Acknowledgements}

The authors acknowledge by financial support provided by Fundação de Amparo à Pesquisa do Estado de São Paulo (FAPESP, process $n^{\circ}$ 2013/03823-8), Coordenação de Aperfeiçoamento de Pessoal de Nível Superior (CAPES, process $\left.n^{\circ} 3886 / 2014\right)$ and Conselho Nacional de Desenvolvimento Científico e Tecnológico (CNPq, process $n^{\circ} 152069 / 2016$ ), in Brazil. Special thanks for Fibria and Infibra for providing raw materials the development of this work.

\section{References}

[1] P. Carrara, L. De Lorenzis, Consistent identification of the interfacial transition zone in simulated cement microstructures, Cem. Concr. Compos 80 (2017) 224-234, https://doi.org/10.1016/j.cemconcomp.2017.03.008.

[2] K.L. Scrivener, A.K. Crumbie, P. Laugesen, The interfacial transition zone (ITZ) between cement paste and aggregate in concrete, Interface Sci. 12 (2004) 411-421, https://doi.org/10.1023/B: INTS.0000042339.92990.4c.

[3] S.F. Santos, R.S. Teixeira, H. Savastano Jr., Interfacial transition zone between lignocellulosic fiber and matrix in cement-based composites, in Holmer Savastano Junior (Ed.), Juliano Fiorelli and Sergio Francisco Dos Santos, Woodhead Publishing, 2017, pp. 27-68, https://doi.org/10.1016/ j.actamat.2015.02.029.

[4] S. Ikai, J.R. Reichert, A.V. Rodrigues, V.A. Zampieri, Asbestos-free technology with new high toughness polypropylene (PP) fibers in air-cured Hatschek process, Constr. Build. Mater 24 (2010) 171-180, https://doi.org/10.1016/ j.conbuildmat.2009.06.019.

[5] G.H.D. Tonoli, S.F. Santos, A.P. Joaquim, H. Savastano Jr., Effect of accelerated carbonation on cementitious roofing tiles reinforced with lignocellulosic fibre, Constr. Build. Mater 24 (2010) 193-201, https://doi.org/10.1016/ j.conbuildmat.2007.11.018.

[6] G.H.D. Tonoli, H. Savastano, E. Fuente, C. Negro, A. Blanco, F.A. Rocco Lahr, Eucalyptus pulp fibres as alternative reinforcement to engineered cementbased composites, Ind. Crops Prod. 31 (2010) 225-232, https://doi.org/ 10.1016/j.indcrop.2009.10.009.

[7] R.S.P. Coutts, Wood fibre reinforced cement composites, in: R.N. SWAMY (Ed.), Nat. Fibre Reinf. Cem. Concr, Blackie, Glasgow, 1988, pp. 208-242 (Concrete Technology and Design, 5), 1988.

[8] R.S. Teixeira, G.H.D. Tonoli, S.F. Santos, J. Fiorelli, H. Savastano Jr., F.A.R. Lahr, Extruded cement based composites reinforced with sugar cane bagasse fibres, Key Eng. Mater 517 (2012) 450-457, https://doi.org/10.4028/www.scientific.net/KEM.517.450.

[9] J. Aveston, A. Kelly, Theory of multiple fracture of fibrous composites, J. Mater Sci. 8 (1973) 352-362, https://doi.org/10.1007/BF00550155.

[10] Y. Shao, S. Moras, N. Ulkem, G. Kubes, Wood fibre - cement composites by extrusion, Can. J. Civ. Eng. 27 (2000) 543-552, https://doi.org/10.1139/cjce27-3-543.

[11] H. Savastano Jr., V. Agopyan, Transition zone studies of vegetable fibre-cement paste composites, Cem. Concr. Compos 21 (1999) 49-57, https://doi.org
10.1016/S0958-9465(98)00038-9.

[12] H. Savastano Jr., V. Agopyan, A.M. Nolasco, L. Pimentel, Plant fibre reinforced cement components for roofing, Constr. Build. Mater 13 (1999) 433-438, https://doi.org/10.1016/S0950-0618(99)00046-X.

[13] W. Zhu, P.J.M. Bartos, Application of depth-sensing microindentation testing to study of interfacial transition zone in reinforced concrete, Cem. Concr. Res. 30 (2000) 1299-1304, https://doi.org/10.1016/S0008-8846(00)00322-7.

[14] S. Wei, J.A. Mandel, S. Said, Study of the interface strength in steel fiberreinforced cement-based composites, J. Proc. 83 (1986) 597-605.

[15] W.M. Cross, K.H. Sabnis, L. Kjerengtroen, J.J. Kellar, Microhardness testing of fiber-reinforced cement paste, Mater. J. 97 (2000) 162-167.

[16] W. Oliver, G. Pharr, An improved technique for determining hardness and elastic modulus using load and displacement sensing indentation experiments, Mater. Res. Soc. 7 (1992) 1564-1583.

[17] W.R.L. Da Silva, J. Němeček, P. Štemberk, Methodology for nanoindentationassisted prediction of macroscale elastic properties of high performance cementitious composites, Cem. Concr. Compos 45 (2014) 57-68, https:// doi.org/10.1016/j.cemconcomp.2013.09.013.

[18] G.H.D. Tonoli, E. Fuente, C. Monte, H. Savastano Jr., F.A. Rocco Lahr, A. Blanco, Effect of fibre morphology on flocculation of fibre-cement suspensions, Cem. Concr. Res. 39 (2009) 1017-1022, https://doi.org/10.1016/j.cem conres.2009.07.010.

[19] ASTM C 150, American Society for Testing and Materials - ASTM C150/ C150M-11. Standard Specification for Portland Cement.

[20] Y.J.M. Soto, G.H.D. Tonoli, R.S. Teixeira, S.F. Santos, H. Savastano Jr., Prospective study on vegetable wastes as reinforcement in extruded fibre-cement, in: Int. Conf. Non-conventional Mater. Technol. Ecol. Mater. Technol. Sustain. Constr, 2007. Maceió. Anais do Brasil-NOCMAT. (Abmtenc) Maceió., 2007.

[21] S.F. Santos, R. Schmidt, A.E.F.S. Almeida, G.H.D. Tonoli, H. Savastano Jr., Supercritical carbonation treatment on extruded fibre-cement reinforced with vegetable fibres, Cem. Concr. Compos 56 (2015) 84-94, https://doi.org/ 10.1016/j.cemconcomp.2014.11.007.

[22] G.H.D. Tonoli, U.P. Rodrigues Filho, H. Savastano Jr., J. Bras, M.N. Belgacem, F.A. Rocco Lahr, Cellulose modified fibres in cement based composites, Compos. Part A Appl. Sci. Manuf. 40 (2009) 2046-2053, https://doi.org/10.1016/ j.compositesa.2009.09.016.

[23] G.H.D. Tonoli, S.F. Santos, R.S. Teixeira, M.A. Pereira-Da-Silva, F.A.R. Lahr, F.H. Pescatori Silva, H. Savastano Jr., Effect of eucalyptus pulp refining on the performance and durability of fibre-cement composites, J. Trop. For. Sci. 25 (2013) 400-409.

[24] E. Ruiz-Agudo, K. Kudłacz, C.V. Putnis, A. Putnis, C. Rodriguez-Navarro, Dissolution and carbonation of portlandite $[\mathrm{Ca}(\mathrm{OH}) 2]$ single crystals, Environ. Sci. Technol. 47 (2013) 11342-11349, https://doi.org/10.1021/es402061c.

[25] J.A. Larbi, J.M.J.M. Bijen, Interaction of polymers with portland cement during hydration. A study, Cem. Concr. Res. 20 (1990) 139-147, https://doi.org/ 10.1016/0008-8846(90)90124-G.

[26] M.U.K. Afridi, Z.U. Chaudhary, Y. Ohama, K. Demura, M.Z. Iqbal, Effects of polymer modification on the formation of high sulphoaluminate or ettringite type (AFt) crystals in polymer-modified mortars, Cem. Concr. Res. 24 (1994) 1492-1494, https://doi.org/10.1016/0008-8846(94)90163-5.

[27] H.F.W. Taylor, Cement Chemistry, Academic press limited, London, 1990.

[28] J.I. Escalante-Garcia, G. Mendoza, J.H. Sharp, Indirect determination of the Ca/ Si ratio of the C-S-H gel in Portland cements, Cem. Concr. Res. 29 (1999) 1999-2003, https://doi.org/10.1016/S0008-8846(99)00191-X. 
[29] B.J. Mohr, J.J. Biernacki, K.E. Kurtis, Microstructural and chemical effects of wet/dry cycling on pulp fiber-cement composites, Cem. Concr. Res. 36 (2006) 1240-1251, https://doi.org/10.1016/j.cemconres.2006.03.020.

[30] X.H. Wang, S. Jacobsen, J.Y. He, Z.L. Zhang, S.F. Lee, H.L. Lein, Application of nanoindentation testing to study of the interfacial transition zone in steel fiber reinforced mortar, Cem. Concr. Res. 39 (2009) 701-715, https://doi.org/ 10.1016/j.cemconres.2009.05.002.

[31] S. Igarashi, A. Bentur, S. Mindess, Microhardness testing of cementitious materials, Adv. Cem. Based Mater 4 (1996) 48-57, https://doi.org/10.1016/ 1065-7355(96)00035-1.

[32] J. Meček, P. Kabele, Z. Bittnar, Nanoindentation based assessment of micromechanical properties of fibre reinforced cementitious composite, in: 6th RILEM Symp. Fibre Reinf. Concr., BEFIB, 2004, pp. 401-410. Varenna, Italy, (2004) pp. 401-410, 2004.

[33] H.L. Rossetto, M.F. de Souza, V.C. Pandolfelli, Adesão em materiais cimentícios: "In-built nanotechnology", Cerâmica 55 (2009) 199-205 (in portuguese).

[34] K. Velez, S. Maximilien, D. Damidot, G. Fantozzi, F. Sorrentino, Determination by nanoindentation of elastic modulus and hardness of pure constituents of Portland cement clinker, Cem. Concr. Res. 31 (2001) 555-561, https://doi.org/
10.1016/S0008-8846(00)00505-6.

[35] A. Bentur, S.A.S. Akers, The microstructure and ageing of cellulose fibre reinforced cement composites cured in a normal environment, Int. J. Cem. Compos. Light. Concr. 11 (1989) 99-109, https://doi.org/10.1016/0262 5075(89)90120-6.

[36] R.D. Tolêdo Filho, K. Scrivener, G.L. England, K. Ghavami, Durability of alkalisensitive sisal and coconut fibres in cement mortar composites, Cem. Concr. Compos 22 (2000) 127-143, https://doi.org/10.1016/S0958-9465(99)000396.

[37] B.J. Mohr, H. Nanko, K.E. Kurtis, Durability of thermomechanical pulp fibercement composites to wet/dry cycling, Cem. Concr. Res. 35 (2005) 1646-1649, https://doi.org/10.1016/j.cemconres.2005.04.005.

[38] B.J. Mohr, H. Nanko, K.E. Kurtis, Durability of kraft pulp fiber - cement composites to wet/dry cycling, Cem. Concr. Compos 27 (2005) 435-448, https://doi.org/10.1016/j.cemconcomp.2004.07.006.

[39] G.H.D. Tonoli, A.P. Joaquim, M.-A. Arsène, K. Bilba, H. Savastano Jr., Performance and durability of cement based composites reinforced with refined sisal pulp, Mater. Manuf. Process 22 (2007) 149-156, https://doi.org/10.1080/ 10426910601062065. 